\title{
Voluntary Ethanol Intake Predicts $\kappa$-Opioid Receptor Supersensitivity and Regionally Distinct Dopaminergic Adaptations in Macaques
}

\author{
Cody A. Siciliano, ${ }^{1}$ Erin S. Calipari, ${ }^{1}$ Verginia C. Cuzon Carlson, ${ }^{2}$ Christa M. Helms, ${ }^{2}$ David M. Lovinger, ${ }^{3}$ \\ Kathleen A. Grant, ${ }^{2}$ and $₫$ Sara R. Jones ${ }^{1}$ \\ ${ }^{1}$ Department of Physiology and Pharmacology, Wake Forest School of Medicine, Winston-Salem, North Carolina 27157, ${ }^{2}$ Division of Neuroscience, Oregon \\ National Primate Research Center, Oregon Health \& Science University, Beaverton, Oregon 97006, and ${ }^{3}$ Laboratory for Integrative Neuroscience, Section on \\ Synaptic Pharmacology, National Institute on Alcohol Abuse and Alcoholism, National Institutes of Health, Rockville, Maryland 20832
}

The dopaminergic projections from the ventral midbrain to the striatum have long been implicated in mediating motivated behaviors and addiction. Previously it was demonstrated that $\kappa$-opioid receptor (KOR) signaling in the striatum plays a critical role in the increased reinforcing efficacy of ethanol following ethanol vapor exposure in rodent models. Although rodents have been used extensively to determine the neurochemical consequences of chronic ethanol exposure, establishing high levels of voluntary drinking in these models has proven difficult. Conversely, nonhuman primates exhibit similar intake and pattern to humans in regard to drinking. Here we examine the effects of chronic voluntary ethanol self-administration on dopamine neurotransmission and the ability of KORs to regulate dopamine release in the dorsolateral caudate (DLC) and nucleus accumbens (NAc) core. Using voltammetry in brain slices from cynomolgus macaques after 6 months of ad libitum ethanol drinking, we found increased KOR sensitivity in both the DLC and NAc. The magnitude of ethanol intake predicted increases in KOR sensitivity in the NAc core, but not the DLC. Additionally, ethanol drinking increased dopamine release and uptake in the NAc, but decreased both of these measures in the DLC. These data suggest that chronic daily drinking may result in regionally distinct disruptions of striatal outputs. In concert with previous reports showing increased KOR regulation of drinking behaviors induced by ethanol exposure, the strong relationship between KOR activity and voluntary ethanol intake observed here gives further support to the hypothesis that KORs may provide a promising pharmacotherapeutic target in the treatment of alcoholism.

Key words: $\kappa$-opioid receptor; caudate; dopamine; nonhuman primate; nucleus accumbens; voltammetry

\section{Introduction}

Although alcoholism is one of the most prevalent disorders in the United States, with over 18 million individuals meeting the criteria for an alcohol use disorder, the neurobiological bases of this condition remain obscure (Substance Abuse and Mental Health Services Administration, 2012). Due to genetic and neuroanatomical similarities, nonhuman primate models of ethanol use allow for high translational validity in investigations of the neurobiological basis of alcohol use disorders (Grant et al., 2014). Additionally, nonhuman primates will voluntarily consume ethanol (Grant et al., 2008) with similar intakes and patterns to those

\footnotetext{
Received Nov. 25, 2014; revised Feb. 24, 2015; accepted Feb. 24, 2015.

Author contributions: C.A.S., E.S.C., D.M.L., K.A.G., and S.R.J. designed research; C.A.S., E.S.C., and C.M.H. performed research; C.A.S. and E.S.C. analyzed data; C.A.S., E.S.C., V.C.C.C., K.A.G., and S.R.J. wrote the paper.

This work was supported by NIH Grants U01 AA014091, P01 AA021099 (S.R.J.), F31 DA031533 (E.S.C.), F31 DA037710, T32 AA007565 (C.A.S.), P51 0D011092, R24 AA019431, and P60 AA10760 (K.A.G.); the Division of Intramural Clinical and Biomedical Research, National Institute of Alcohol Abuse and Alcoholism (D.M.L.), and Integrative Neuroscience Initiative on Alcoholism Grant AA13510 (K.A.G.).

The authors declare no competing financial interests.

Correspondence should be addressed to Dr. Sara R. Jones, Department of Physiology and Pharmacology, Wake Forest School of Medicine, Medical Center Boulevard, Winston-Salem, NC 27157. E-mail: srjones@wakehealth.edu. DOI:10.1523/JNEUROSCI.4820-14.2015

Copyright $\odot 2015$ the authors $\quad 0270-6474 / 15 / 355959-10 \$ 15.00 / 0$
}

of humans (Majchrowicz and Mendelson, 1970). This allows for volitional models of ethanol use, which accurately mimic the contingent process in which humans consume ethanol.

Natural and drug reinforcement as well as incentive motivational processes are mediated, at least in part, by dopaminergic signaling in the nucleus accumbens (NAc), caudate, and putamen (Carelli, 2002). The NAc is divided into two subregions, the core and shell. While both receive dense dopaminergic innervation from the ventral tegmental area, they differ in efferent connections. For example, NAc core outputs target the substantia nigra and dorsolateral ventral pallidum, and the NAc shell projects to the ventral tegmental area, medial ventral pallidum, and extended amygdala (Heimer et al., 1991). The two structures vary in function as well: the core is integral in reward-prediction error encoding and integrates environmental and motivational information to guide motor outputs, whereas the shell mediates the acute reinforcing effects of abused drugs and is involved in pavlovian conditioning and incentive processes (Ongür and Price, 2000; Di Chiara, 2002; Saddoris et al., 2013). Indeed, the NAc core and shell control different aspects of drug seeking; blockade of $\mathrm{D}_{1}$-type dopamine (DA) receptors in the shell inhibits contextinduced reinstatement of drug seeking, whereas the NAc core 
mediates reinstatement induced by discrete cues (Bossert et al., 2007). On the other hand, the putamen and the precommisural dorsolateral caudate (DLC) receive input from the sensorimotor cortex and mediate habitual drug-taking behaviors that develop after chronic administration (Graybiel, 1995, 2008; Porrino et al., 2004). Thus, understanding the dopaminergic inputs to these regions may give insight into dynamic changes in dopaminergic signaling associated with alcoholism.

Of the many receptors that regulate presynaptic DA signaling, the $\kappa$-opioid receptor (KOR) is of particular interest, as its activation attenuates striatal DA release, cell excitability, and DA synthesis (Walker et al., 1987; Werling et al., 1988; Manzanares et al., 1991). A previous hypothesis that has gained considerable traction in the literature is that ethanol-induced dysregulation of the dynorphin/KOR system mediates increased ethanol drinking and reinforcement produced by ethanol use (Walker and Koob, 2008; Walker et al., 2012). Following ethanol self-administration in macaques, we used fast-scan cyclic voltammetry (FSCV) in brain slices containing the NAc core or the precommisural DLC to determine the dopaminergic adaptations and changes in KOR sensitivity that may underlie drinking behaviors. We hypothesized that DA terminal function and KOR sensitivity would be altered in a manner proportional to ethanol intake.

\section{Materials and Methods}

Subjects. Eleven male cynomolgus monkeys (Macaca fascicularis) between the ages of 5.9 and 6.9 years were used for the current study. Animals were individually housed in quadrant cages $(0.8 \times 0.8 \times 0.9 \mathrm{~m})$ with constant temperature $\left(20-22^{\circ} \mathrm{C}\right)$ and humidity $(65 \%)$ and an $11 \mathrm{~h}$ light cycle (lights on at 8:00 AM). Animals had visual, auditory, and olfactory contact with other conspecifics, in addition to $2 \mathrm{~h}$ of pair housing each weekday. Body weights were measured weekly. All procedures were conducted in accordance with the Guide for the Care and Use of Laboratory Animals and approved by the Oregon National Primate Research Center Institutional Animal Care and Use Committee.

Drinking procedure. Monkeys (eight ethanol and three control) were trained to obtain fluids and their meals from an operant panel that replaced one of the walls of their home cage, as described previously (Vivian et al., 2001; Grant et al., 2008). Briefly, the panels had two spouts, one to each side of a 15 inch video display screen. Near each spout, the display showed a set of three stimulus lights (white, red, and green) that indicated an active session or food or fluid availability, respectively. A centrally located recessed dowel activated the fluid spouts, and an infrared finger poke activated the pellet dispenser (env-203-1000; Med Associates). Each spout was connected via Nalgene tubing to a $1 \mathrm{~L}$ fluid reservoir set on a digital scale (Adventurer Pro Balances AV4101C; Ohaus). Dowel pulls, finger pokes, and fluid consumption were recorded every $500 \mathrm{~ms}$ via a computerized system (Dell Optiplex) using custom hardware and programming using a National Instruments interface and Labview software. Schedule-induced polydipsia, as described previously (Vivian et al., 2001; Grant et al., 2008), was used to induce ethanol selfadministration in daily $16 \mathrm{~h}$ sessions. Briefly, a $1 \mathrm{~g}$ banana food pellet (Research Diets) was dispensed every $300 \mathrm{~s}$ (fixed time, $300 \mathrm{~s}$ ) until a water volume equivalent to $1.5 \mathrm{~g} / \mathrm{kg}$ of $4 \%(\mathrm{w} / \mathrm{v}$ ) ethanol was consumed. Following water induction, $4 \%$ ethanol replaced water. In 30 day increments, each animal consumed increasing doses of $4 \%$ ethanol: $0.5 \mathrm{~g} / \mathrm{kg} / \mathrm{d}, 1.0 \mathrm{~g} / \mathrm{kg} / \mathrm{d}$, then $1.5 \mathrm{~g} / \mathrm{kg} / \mathrm{d}$. Following consumption of the programmed volume, water was immediately available, and any remaining pellets were available on a fixed-ratio 1 (FR-1) schedule after $2 \mathrm{~h}$. Following completion of ethanol induction, daily $22 \mathrm{~h}$ sessions were performed, during which water and ethanol were concurrently available. Food pellets were available on a FR-1 schedule in at least three daily meals in $2 \mathrm{~h}$ intervals starting at the session onset. Data were downloaded, husbandry tasks were performed, food and fluids were replenished, and fresh fruit was provided each day by technicians during the $2 \mathrm{~h}$ break.
Blood ethanol concentration. Monkeys were trained to present their leg from their home cage for awake venipuncture. Blood was collected for blood ethanol concentration (BEC) measurement every 5-7 d. BEC was measured via gas head-space chromatography.

Tissue preparation. Tissue preparation was described previously (Daunais et al., 2010; Cuzon Carlson et al., 2011). Briefly, monkeys were anesthetized with ketamine $(10 \mathrm{mg} / \mathrm{kg})$, maintained on isoflurane, and perfused with ice-cold oxygenated monkey perfusion solution [containing (in $\mathrm{mM}$ ) $124 \mathrm{NaCl}, 23 \mathrm{NaHCO}_{3}, 3 \mathrm{NaH}_{2} \mathrm{PO}_{4}, 5 \mathrm{KCl}, 2 \mathrm{MgSO}_{4}, 10$ D-glucose, $2 \mathrm{CaCl}_{2}$ ]. Brains were quickly removed and sectioned along the coronal plane using a brain matrix (Electron Microscopy Sciences), with the brain knife position guided by each individual's MRI. An isolated tissue block containing only the striatum (caudate, putamen, and nucleus accumbens) was placed in ice-cold oxygenated monkey perfusion solution and transported on ice for slicing.

In vitro voltammetry. Animals were allowed ethanol access until the morning of necropsy. The brain was removed $\sim 3.5-6.5 \mathrm{~h}$ after the last ethanol access. A normal pattern of water and ethanol drinking occurred the day before necropsy, and monkeys were sedated $0-3 \mathrm{~h}$ from the time they would typically begin their daily drinking session. FSCV was then used to characterize presynaptic DA release and uptake as well as the ability of KORs to decrease DA release, or KOR sensitivity, in the DLC and NAc core. Voltammetric detection of DA in brain slices has been used by the authors and others to examine receptor regulation of DA release and uptake kinetics (Kelly and Wightman, 1987; Patel and Rice, 2013; Siciliano et al., 2014, 2015). A ceramic blade attached to a vibrating tissue slicer was used to prepare $250-\mu \mathrm{m}$-thick coronal brain sections containing the DLC and NAc core. The tissue was immersed in oxygenated artificial CSF (aCSF) containing the following (in mM): $126 \mathrm{NaCl}$, $2.5 \mathrm{KCl}, 1.2 \mathrm{NaH}_{2} \mathrm{PO}_{4}, 2.4 \mathrm{CaCl}_{2}, 1.2 \mathrm{MgCl}_{2}, 25 \mathrm{NaHCO}_{3}, 11$ glucose, and $0.4 \mathrm{~L}$-ascorbic acid, $\mathrm{pH}$ adjusted to 7.4. Once sliced, the tissue was transferred to testing chambers containing bath aCSF $\left(32^{\circ} \mathrm{C}\right)$, which flowed at $1 \mathrm{ml} / \mathrm{min}$. A carbon fiber microelectrode (100-200 $\mu \mathrm{M}$ length, $7 \mu \mathrm{M}$ diameter) and bipolar stimulating electrode were placed in close proximity on the tissue. Extracellular DA was recorded by applying a triangular waveform ( -0.4 to +1.2 to $-0.4 \mathrm{~V} \mathrm{vs} \mathrm{Ag} / \mathrm{AgCl}, 400 \mathrm{~V} / \mathrm{s})$ to the recording electrode and scanning every $100 \mathrm{~ms}$. This waveform allows for the assessment of oxidation and reduction peaks for DA, and has been used extensively to detect DA in brain (Lemos et al., 2012; Ferris et al., 2013). DA release was evoked by 1 pulse stimulations ( $350 \mu \mathrm{A}, 4 \mathrm{~ms}$, monophasic) applied to the tissue every $5 \mathrm{~min}$. When a stable baseline was established (three collections within $10 \%$ variability) and predrug measures were taken, the selective KOR agonist U50,488 (0.3 $\mu \mathrm{M}$ and 1 $\mu \mathrm{M}$, cumulatively) was bath applied to the slice, and stimulations continued until stability was reached at each concentration.

Data analysis. For all analysis of FSCV data, Demon voltammetry and analysis software was used (Yorgason et al., 2011). Recording electrodes were calibrated by recording responses (in electrical current; in nanoamperes) to a known concentration of DA ( $3 \mu \mathrm{M})$ using a flow-injection system. This was used to convert electrical current to DA concentration. Before application of U50,488, FCSV data were modeled using Michaelis-Menten kinetics, which allows for the determination of evoked DA release and the maximal rate of DA uptake $\left(V_{\max }\right)$.

Ratio analysis. To determine the ethanol-induced changes in the relative DA release and uptake parameters between striatal subregions, we calculated a DLC to NAc core ratio for both DA release and uptake. The DLC to NAc core ratio value for each animal was calculated by dividing the release or uptake measure from the DLC by that from the NAc core. Of the eight ethanol self-administration animals, three animals had recording performed in only one of the two regions, and thus were not able to be included in ratio analysis. No animals were excluded from any of the analyses as a statistical outlier.

Half-life analysis. To determine KOR-induced changes in DA uptake rate, we calculated the half-life of voltammetric signals across the same DA concentration range for controls and drinkers. This analysis was used in lieu of Michaelis-Menten modeling because a requirement of the Michaelis-Menten modeling kinetics is that a saturating concentration of DA is present at the DA transporter (DAT); however, this prerequisite was violated following KOR-induced decreases in DA release. 
A

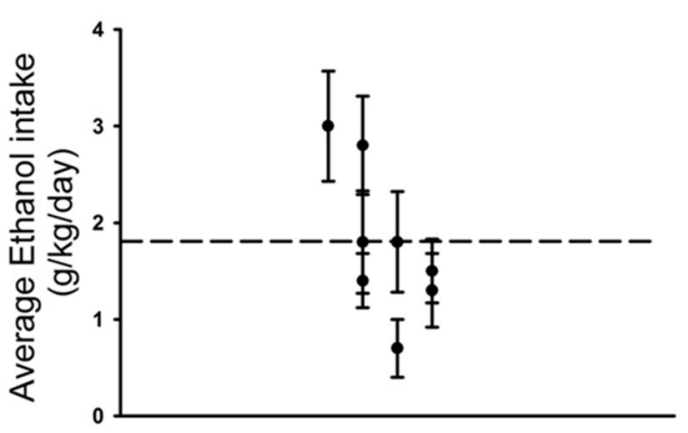

C

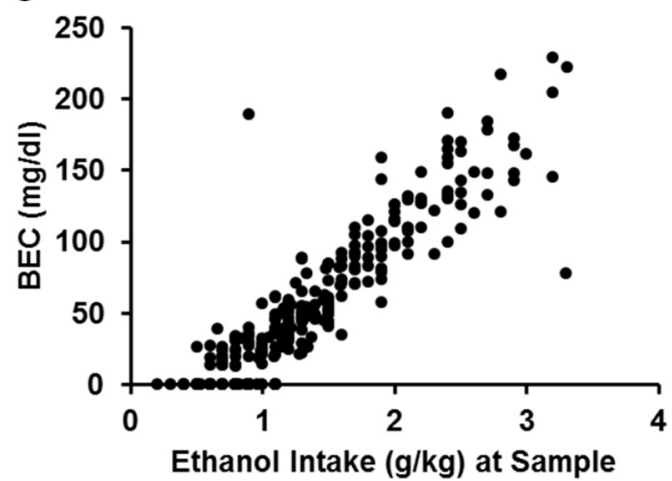

B

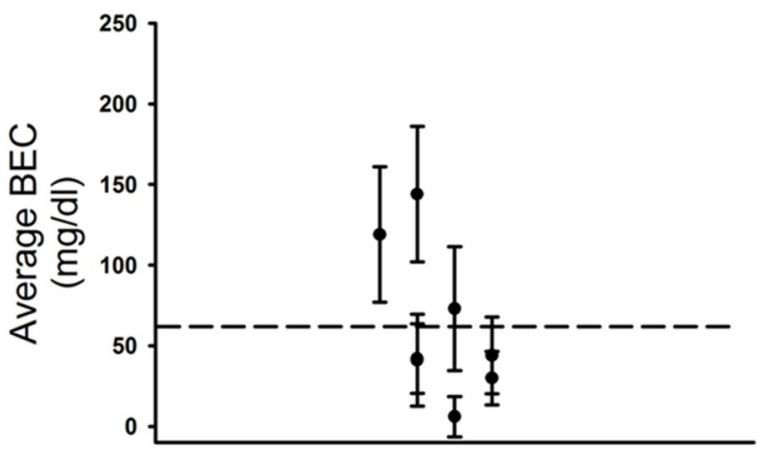

D

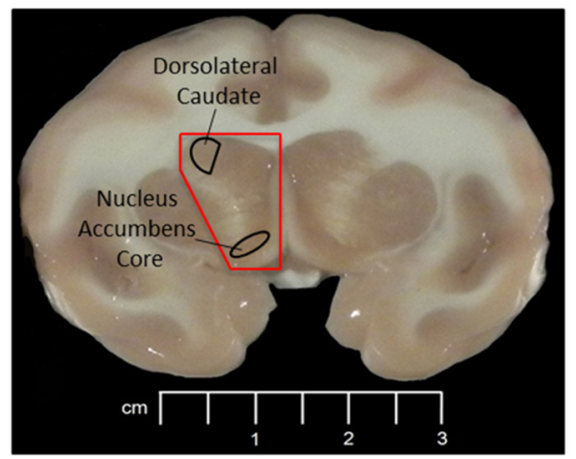

Figure 1. Drinking data and location of electrode placements for voltammetric assessment of DA terminal function. $A$, Average ( \pm SD) daily ethanol intake for each animal. The dashed line represents the group average. $\boldsymbol{B}$, Average ( \pm SD) BEC taken $7 \mathrm{~h}$ after session onset every $5-7 \mathrm{~d}$ over the 6 month access period. The dashed line represents the group average. $C$, Correlation showing a strong positive relationship between BEC measured every $5-7 \mathrm{~d}$ and ethanol intake on the day BEC samples were collected. $\boldsymbol{D}$, Tissue received for slicing following necropsy is outlined in red. Voltammetric experiments were performed in the DLC and NAc core of macaques at approximately $-0.5 \mathrm{~mm}$ (Paxinos et al., 2009).

Statistics. Comparisons of DA kinetics and KOR sensitivity between groups were made using Student's $t$ tests. Data for KOR sensitivity across regions were subject to a repeated-measures two-way ANOVA. When main effects were obtained $(p<0.05)$, differences between groups were tested using a Bonferroni post hoc test. Pearson's correlation coefficients were used to measure the strength of correlation between DA terminal function, KOR sensitivity, and lifetime ethanol intake.

\section{Results}

DA terminal function is decreased in the DLC and increased in the NAc core following voluntary ethanol drinking Animals were allowed access to ethanol for $22 \mathrm{~h} / \mathrm{d}$, and BECs were measured every $5-7 \mathrm{~d}, 7 \mathrm{~h}$ after session onset, as described previously (Grant et al., 2008). Average amounts of ethanol consumed daily varied across individuals and ranged from 0.7 to $3.0 \mathrm{~g} / \mathrm{kg}$ (Fig. 1A). BEC ranged from 6 to $144 \mathrm{mg} / \mathrm{dl}$ (Fig. $1 B$ ) and was highly correlated $(r=0.91 ; n=266 ; p<0.001)$ with ethanol intake at the time the sample was taken, $7 \mathrm{~h}$ into the start of the $22 \mathrm{~h}$ session (Fig. 1C). FSCV was used to assess DA release and uptake in slices containing the DLC or NAc core (Fig. 1D). We found that slices from ethanol self-administration monkeys had reduced DA release in the DLC compared to controls (Fig. 2A-C; $t_{7}=3.044 ; p=0.0094 ; 95 \% \mathrm{CI}, 0.099$ to 0.790 ). Additionally, we found reduced $V_{\max }$ in the DLC in ethanol drinkers (Fig. $2 D, E ; t_{7}=2.52 ; p=0.040 ; 95 \% \mathrm{CI}, 0.047$ to 1.509 ). . 0 determine whether the ethanol-induced changes to DA terminal function could be associated with ethanol-drinking behaviors, voltammetric measures were correlated with total ethanol intake over the 6 month ethanol free-access period. DA release did not correlate with ethanol intake in the DLC (Fig. $2 F ; r=0.33 ; p=0.26 ; 95 \% \mathrm{CI}$, -0.659 to $0.900 ; \beta=0.00052 \pm 0.00075)$. We also found only a trend between DA uptake rate and ethanol intake (Fig. 2G; $r=0.71$; $p=0.056 ; 95 \%$ CI, -0.235 to $0.966 ; \beta=0.0021 \pm 0.0010$ ).

We found an opposite effect of ethanol drinking in the NAc core, where DA release (Fig. $3 A-C ; t_{8}=2.38 ; p=0.044 ; 95 \% \mathrm{CI}$, -0.958 to -0.016 ) and uptake (Fig. $3 D, E ; t_{8}=2.70 ; p=0.027$; $95 \% \mathrm{CI},-0.788$ to -0.061 ) were increased in ethanol drinking monkeys compared to controls. We found no relationship between DA release and lifetime ethanol intake (Fig. 3F; $r=0.13$; $p=0.39 ; 95 \% \mathrm{CI},-0.6883$ to $0.8061 ; \beta=0.00036 \pm 0.0012$ ), or DA uptake rate and ethanol intake (Fig. $3 G ; r=-0.56 ; p=0.096$, $95 \% \mathrm{CI},-0.9236$ to $0.3338 ; \beta=-0.0011 \pm 0.00071)$.

Previous reports in rodents have outlined the integral role of DA-dependent NAc core-to-DLC communication in the development of aberrant drug-taking and drug-seeking behaviors (Belin and Everitt, 2008; Everitt and Robbins, 2013). Indeed, in macaques, activation of striatal regions during drug selfadministration shifts from ventral to dorsal as drug use persists, further highlighting the importance of the relative contributions of the NAc core and DLC to the control of behavior (Porrino et al., 2004). Although previous work supporting the hypothesis of a ventral-todorsal shift in the locus of dopaminergic control of drug taking and seeking has focused on psychostimulants, here we determined the relative dopaminergic activity of the two structures as it relates to ethanol self-administration by calculating a DLC/NAc core ratio of $D A$ release and uptake. We hypothesized that the relative magnitude of DA signaling between the NAc core and the DLC may be an important determinant of chronic ethanol self-administration. Measurements of DA release and uptake were taken only from one region in some animals; thus, some animals were excluded from the ratio analysis. We found that, indeed, drinkers exhibited a lower 


\section{Dorsolateral Caudate}

A
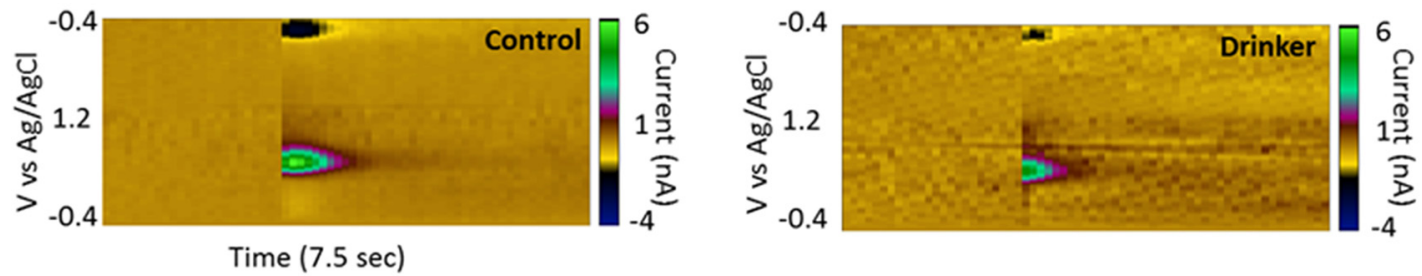

B
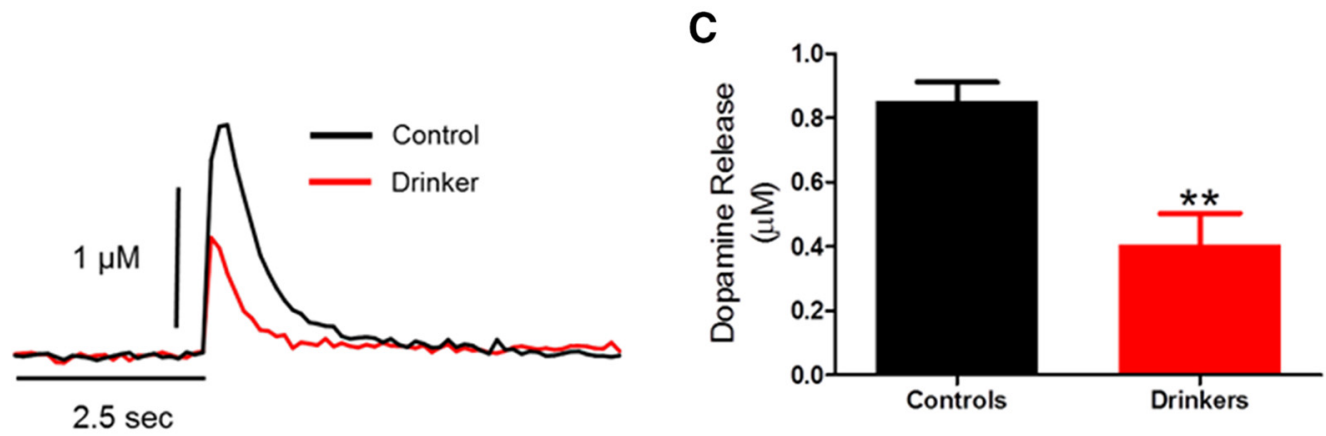

D
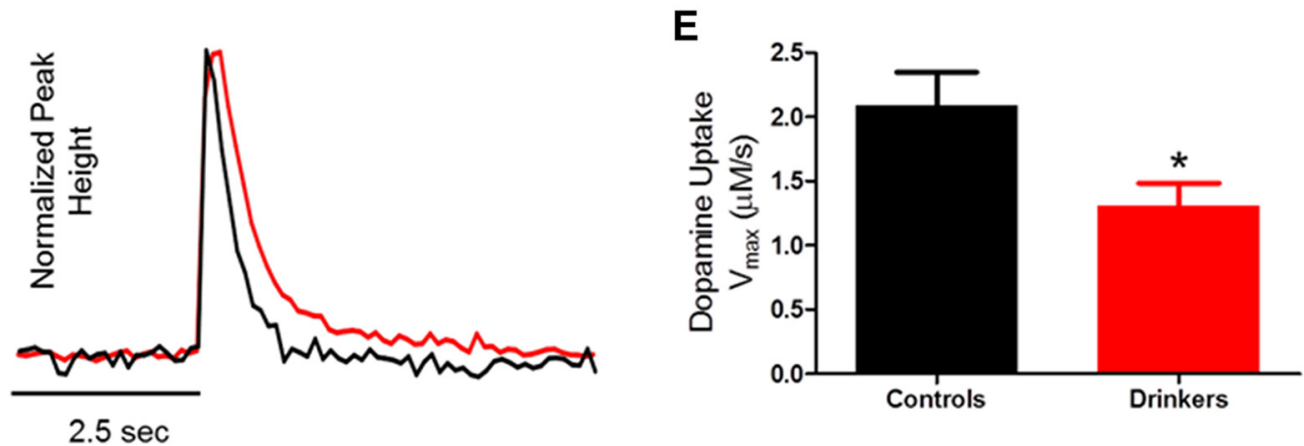

$\mathbf{F}$

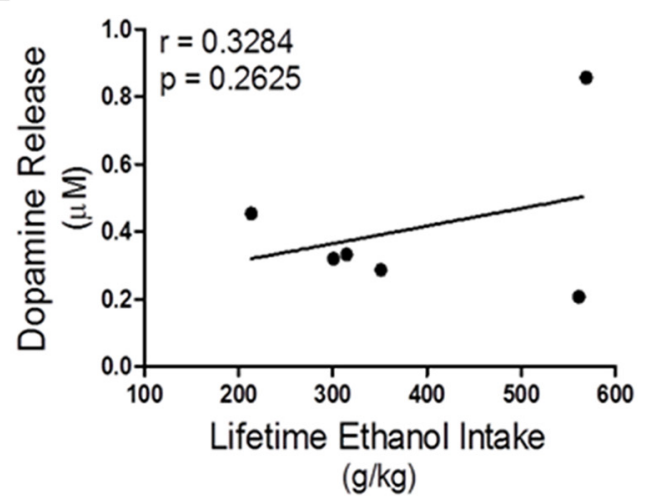

G

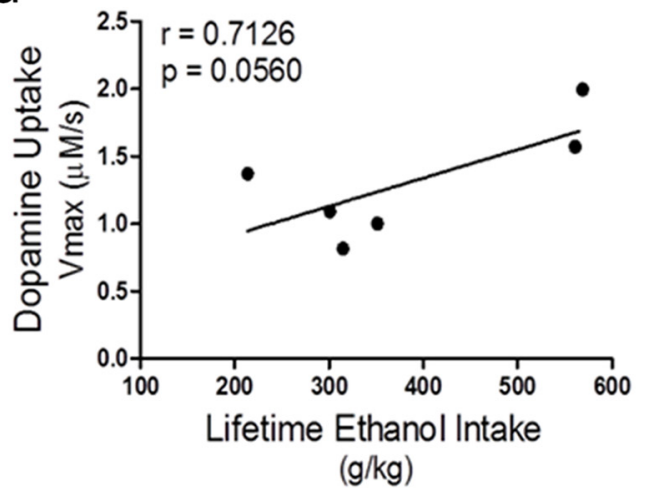

Figure 2. DA release and uptake in the DLC are decreased following ethanol self-administration. $A, D A$ ( $z$-axis), as indicated by its oxidation at $+0.6 \mathrm{~V}$ and reduction at $-0.2 \mathrm{~V}$ ( $y$-axis), across time (x-axis) is represented as pseudocolor plots for controls (left) and drinkers (right). $\boldsymbol{B}$, Representative traces showing decreased DA release in the DLC of drinkers compared to control animals. $\boldsymbol{C}$, Group data ( $n=3$ for controls; $n=6$ for drinkers) indicating decreased evoked DA release. $\boldsymbol{D}$, Representative traces showing decreased DA uptake $\left(V_{\max }\right)$ following ethanol self-administration. $\boldsymbol{E}$, Group data showing decreased DA uptake in drinkers compared to controls. $F$, Correlation analysis showing no relationship between ethanol intake and DA release in the DLC. $G$, Correlation analysis showing a trend towards a positive relationship between DA uptake and ethanol intake in the DLC. Error bars indicate \pm SEM. ${ }^{*} p<0.05$ versus control; ${ }^{* *} p<0.01$ versus control.

DLC/NAc core ratio for both release (Fig. $4 A ; t_{7}=3.75 ; p=0.0036$; $95 \%$ CI, 0.676 to 2.985 ) and uptake (Fig. $4 B ; t_{5}=2.53 ; p=0.022$; 95\% CI, 0.020 to 1.236 ) compared to controls. We then correlated the ratio of DLC to NAc core DA release and uptake rates with ethanol intake. The DLC to NAc core ratio of DA release was not correlated with ethanol intake (Fig. $4 C ; r=0.48 ; p=0.20$; 95\% CI,
-0.696 to $0.957 ; \beta=0.0005 \pm 0.00050)$; however, the DLC to NAc core ratio of DA uptake rates was highly correlated with ethanol intake (Fig. $4 D ; r=0.98 ; p=0.0015 ; 95 \%$ CI, 0.744 to $0.999 ; \beta=$ $0.0019 \pm 0.00021)$, suggesting that the relative change in DAT function across striatal regions may be functionally linked and related to the amount of ethanol consumed. 


\section{Nucleus Accumbens Core}

A
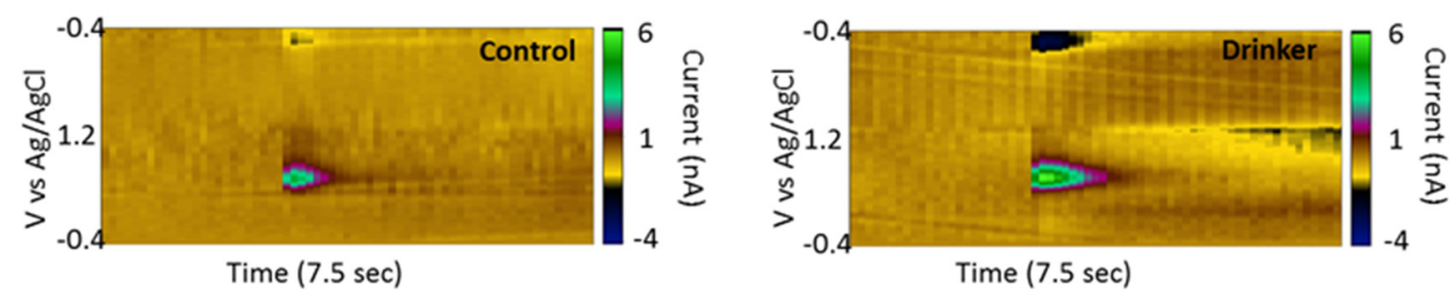

$\mathbf{B}$

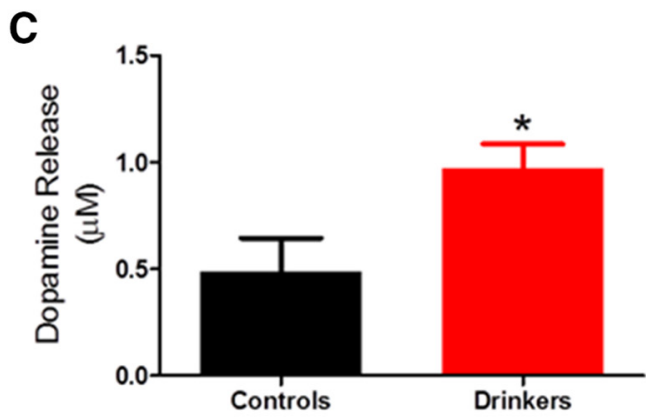

D

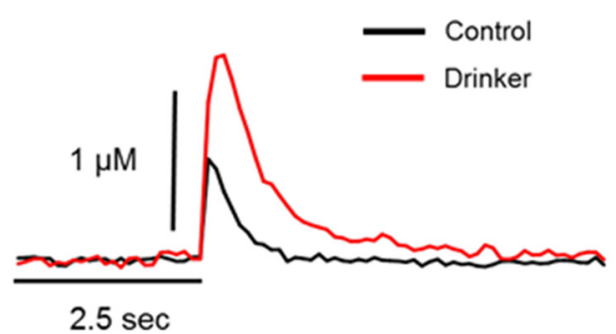

E
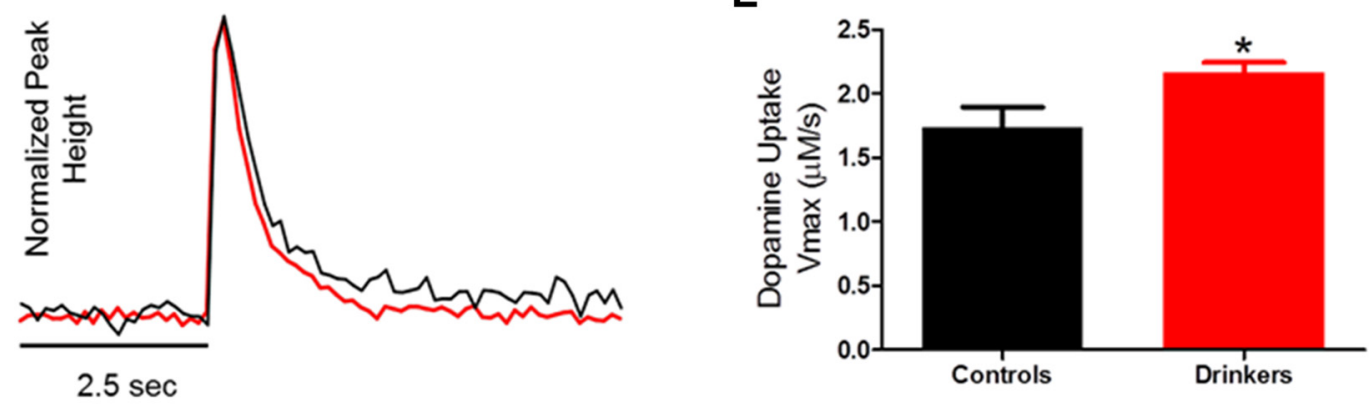

$\mathbf{F}$

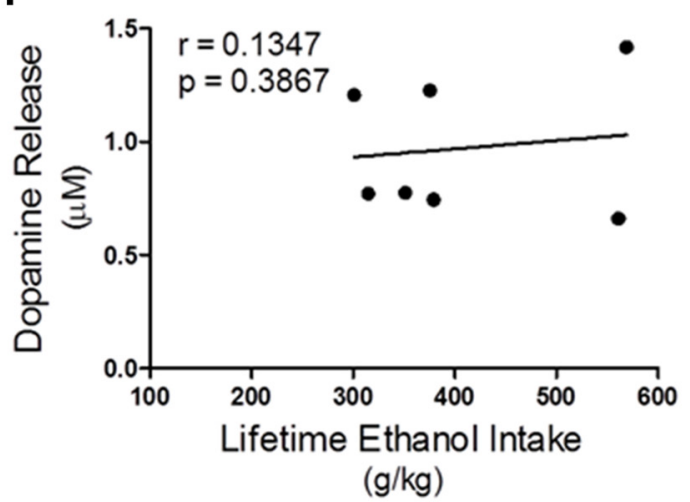

G

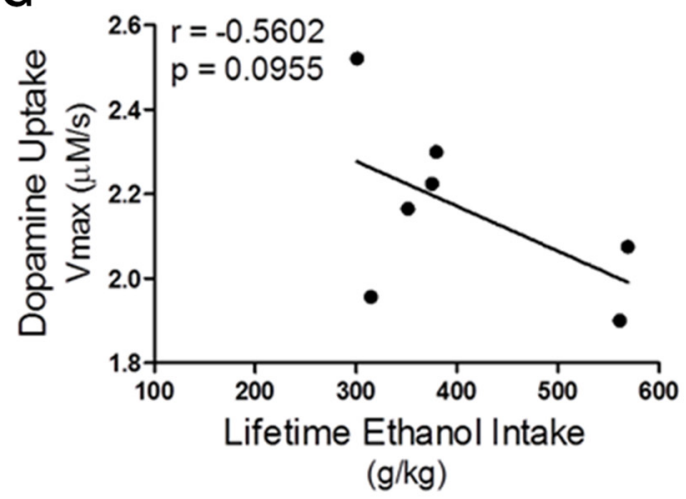

Figure 3. DA release and uptake in the NAc core are increased following ethanol self-administration. $A, D A$ ( $z$-axis), as indicated by its oxidation $+0.6 \mathrm{~V}$ and reduction at $-0.2 \mathrm{~V}$ ( $y$-axis), across time ( $x$-axis) is represented as pseudocolor plots for controls (left) and drinkers (right). $\boldsymbol{B}$, Representative trace showing increased DA release in the NAc core following ethanol self-administration. C, Group data ( $n=3$ for controls; $n=7$ for drinkers) indicating increased release in the NAc core of drinkers compared to control animals. $\boldsymbol{D}$, Representative trace showing increased DA uptake in the NAc core following ethanol self-administration. $\boldsymbol{E}$, Group data showing increased DA uptake in drinkers compared to controls. $\boldsymbol{F}$, Correlation analysis showing no relationship between ethanol intake and DA release in the NAc core. $G$, Correlation analysis showing no relationship between dopamine uptake and ethanol intake. Error bars indicate $\pm S E M .{ }^{*} p<0.05$ versus control.

Ethanol-induced increases in KOR sensitivity are predicted by ethanol intake

Numerous KOR agonists/antagonists are available clinically; thus, understanding how KOR sensitivity relates to drinking behaviors, especially in nonhuman primate models of drinking, may open a novel avenue for therapeutic interventions. Further- more, following repeated ethanol exposure, KOR antagonists elevate DA release, whereas there is no effect in ethanol naive animals, suggesting that ethanol may increase the sensitivity of KORs (Lindholm et al., 2007). Previous literature has demonstrated decreased withdrawal signs, ethanol intake, and reinforcing efficacy in response to administration of a KOR antagonist in 
A
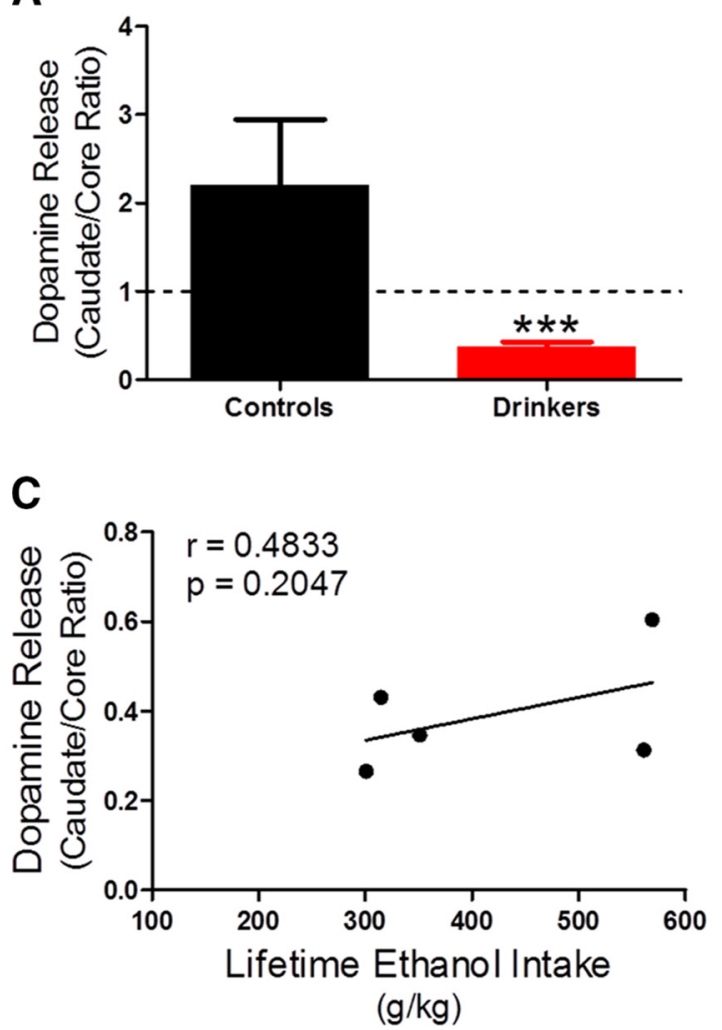

B
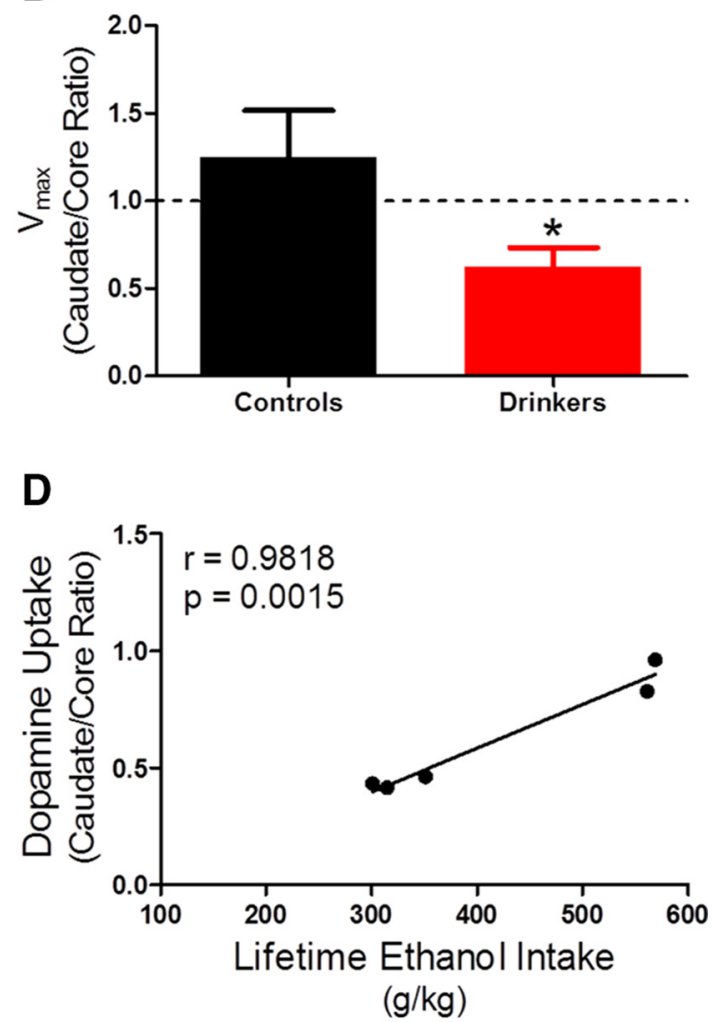

Figure 4. Relative relationship between DA release and uptake across regions is reversed by ethanol self-administration and is predictive of ethanol intake. $\boldsymbol{A}$, DA release expressed as a DLC/NAC core ratio across regions. In control animals, evoked DA release is higher in the DLC than the NAc core. This relationship is reversed following ethanol self-administration. $\boldsymbol{B}$, The maximal rate of uptake $\left(V_{\max }\right)$ is greater in the DLC than the NAc core of control animals. This relationship is reversed in drinkers. C,Correlation analysis showing no relationship between DLC/NAC core ratio of DA release and ethanol intake. $\boldsymbol{D}$, Correlation analysis showing a positive relationship between the DLC/NAc core ratio of DA uptake and ethanol intake. When uptake rates are higher in the NAc core compared to $\mathrm{DLC}$, intake is low, and when uptake rates are equal across regions, intake is high. Error bars indicate $\pm \mathrm{SEM} .{ }^{*} p<0.05$ versus control; ${ }^{* * *} p<0.001$ versus control.

ethanol-dependent rats (Walker and Koob, 2008; Berger et al., 2013); however, changes in KOR signaling following voluntary ethanol drinking remain to be elucidated. Thus, we examined ethanol-induced changes in the ability of KORs to reduce DA release, or KOR sensitivity, through the use of the selective KOR agonist U50,488 $(0.3 \mu \mathrm{M}$ and $1 \mu \mathrm{M})$. These concentrations were selected based on pilot data from our lab indicating that the $\mathrm{IC}_{50}$ for effects of U50,488 on DA release is between $0.3 \mu \mathrm{M}$ and $1 \mu \mathrm{M}$. Based on previous findings in rodents that KOR antagonism reduces ethanol intake in dependent animals while drinking in nondependent animals is unchanged (Walker and Koob, 2008), we hypothesized that KOR sensitivity would be increased following chronic ethanol self-administration. As predicted, U50,488 in the DLC revealed a main effect of concentration (Fig. $5 \mathrm{~A}, \mathrm{C}$; $\left.F_{(1,6)}=68.04, p=0.0002\right)$ and ethanol history $\left(F_{(1,6)}=31.67\right.$, $p=0.0013)$, with a greater decrease from baseline DA release in ethanol drinkers compared to controls at $0.3 \mu \mathrm{M}(p<0.01 ; 95 \%$ CI, 3.674 to 21.15$)$ and $1 \mu \mathrm{M}(p<0.001 ; 95 \% \mathrm{CI}, 12.97$ to 30.45$)$, indicating supersensitivity of KORs. We then correlated the percentage change in DA release induced by $1 \mu \mathrm{M}$ U50,488 with lifetime ethanol intake to determine whether changes in KOR sensitivity were related to chronic ethanol exposure. Correlation analysis showed no relationship between KOR sensitivity in the DLC and cumulative ethanol intake (Fig. $5 E ; r=0.19 ; p=0.38$; 95\% CI, -0.831 to $0.919 ; \beta=0.010 \pm 0.030)$.

Similarly, in the NAc core, a two-way repeated measures ANOVA revealed a main effect of concentration (Fig. $5 B, D ; F_{(1,8)}=$ $33.68, p=0.0004)$ and ethanol history $\left(F_{(1,8)}=10.63, p=0.012\right)$. A
Bonferroni post hoc analysis revealed a greater of effect of U50,488 in NAc core of ethanol drinkers at $0.3 \mu \mathrm{M}(p<0.05 ; 95 \%$ CI, 5.128 to 52.81). Unlike in the DLC, in the NAc core there was a positive relationship between ethanol intake and KOR sensitivity to $1 \mu \mathrm{M}$ U50,488 (Fig. $5 F ; r=0.67 ; p=0.048 ; 95 \%$ CI, -0.160 to $0.947 ; \beta=$ $0.072 \pm 0.035)$.

\section{KOR regulation of DA release is greater in the NAc core}

To determine regional differences in response to U50,488 separately in each treatment group, a within-subjects analyses was used. In control animals, main effects of concentration (Fig. 5G; $\left.F_{(1,4)}=21.23, p=0.010\right)$ and region $\left(F_{(1,4)}=8.87, p=0.041\right)$ were observed. A Bonferroni post hoc analysis revealed significantly greater U50,488 attenuation of DA release in the NAc as compared to the DLC at $1 \mu \mathrm{M}(p<0.05 ; 95 \% \mathrm{CI}, 8.665$ to 55.11$)$. Similarly, in drinkers, there were main effects of concentration (Fig. $\left.5 H ; F_{(1,10)}=17.82, p=0.0018\right)$ as well as region $\left(F_{(1,10)}=\right.$ $61.19, p=0.0001)$. Bonferroni post hoc analysis revealed significantly greater U50,488-induced attenuation of DA release in the NAc compared to the DLC at $0.3 \mu \mathrm{M}(p<0.05 ; 95 \%$ CI, 3.088 to $36.17)$ and $1 \mu \mathrm{M}(p<0.001 ; 95 \% \mathrm{CI}, 15.44$ to 48.52$)$. These results are consistent with rodent literature showing greater availability of KORs in the NAc compared to dorsal regions of the striatum (Le Merrer et al., 2009).

\section{KORs regulate DA uptake in the DLC}

Previous reports have demonstrated that KOR activation may alter DA uptake rates in addition to affecting DA release (Das et 
Dorsolateral Caudate

A

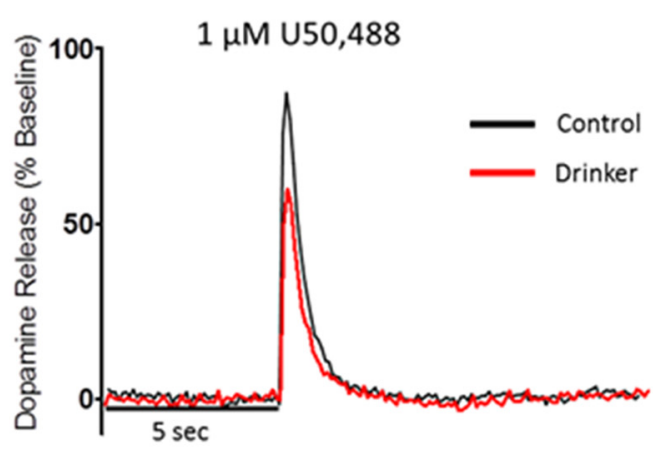

C

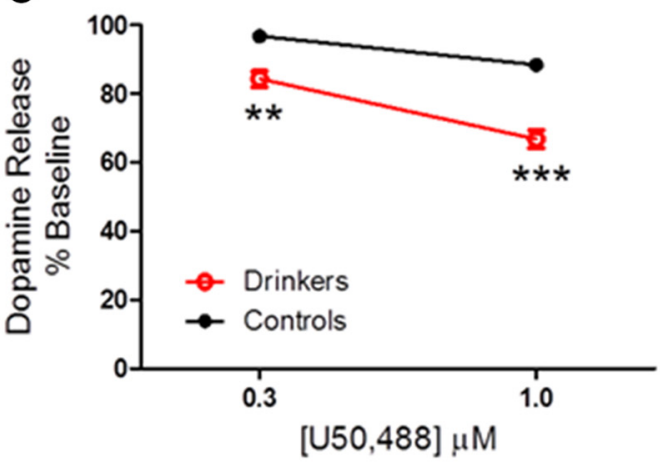

E

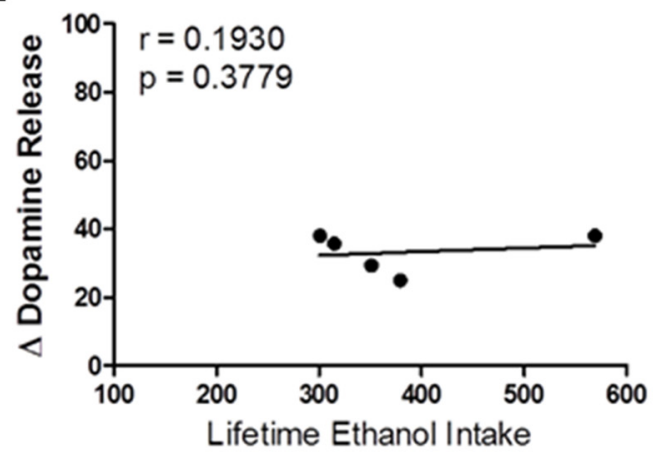

$(\mathrm{g} / \mathrm{kg})$

G

Controls

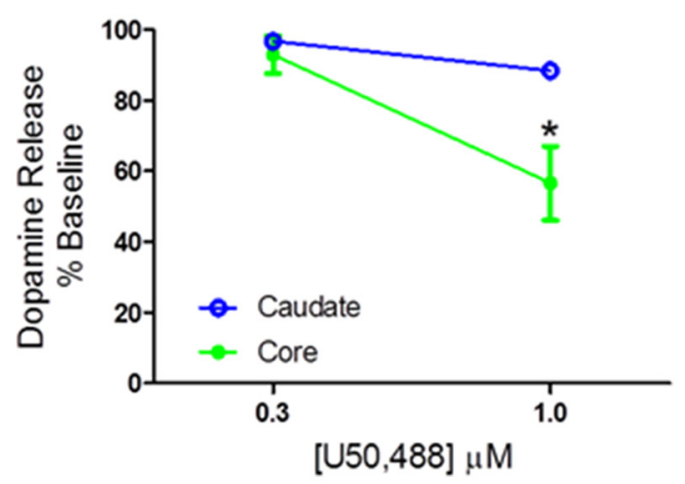

Nucleus Accumbens Core

B

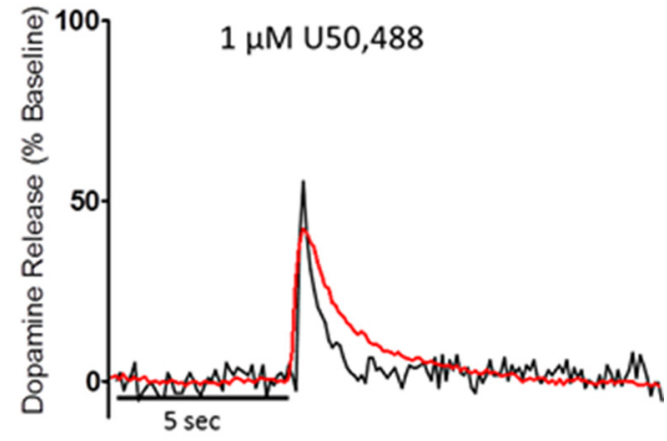

D

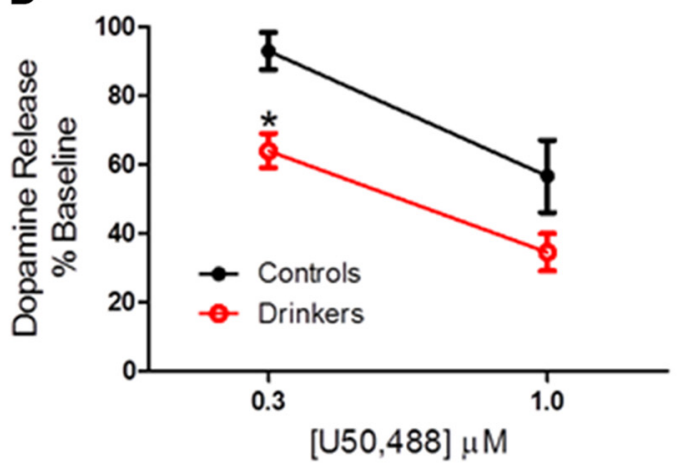

$\mathbf{F}$

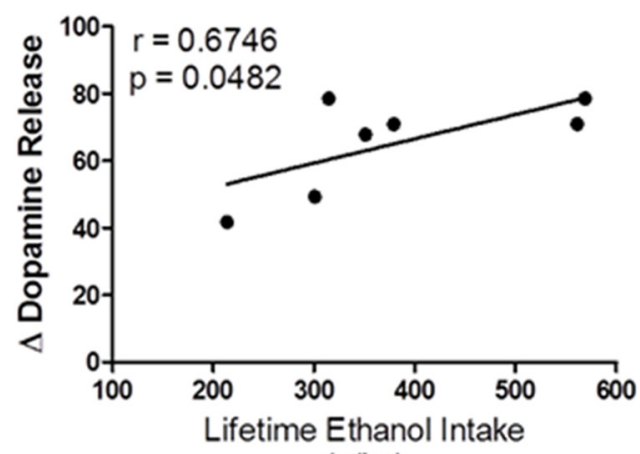

$(\mathrm{g} / \mathrm{kg})$

H

Drinkers

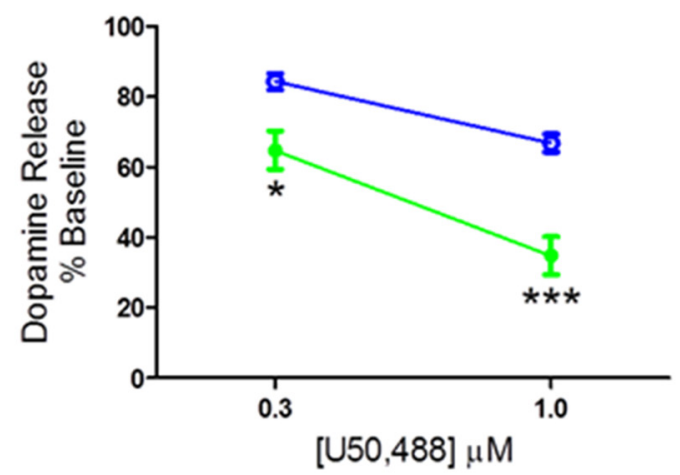

Figure 5. KOR sensitivity in the NAc core is increased by ethanol self-administration and predicted by ethanol intake. $A$, Representative traces illustrating augmented U50,488-induced attenuation of DA release in the DLC of drinkers compared to control animals. $B$, Representative traces showing augmented U50-induced attenuation of DA release in the NAc core of drinkers compared to control animals. C, Group data ( $n=3$ for controls; $n=6$ for drinkers) indicating supersensitive KORs in the DLC of drinking animals. D, Group data ( $n=3$ (Figure legend continues.) 
A

Dorsolateral Caudate

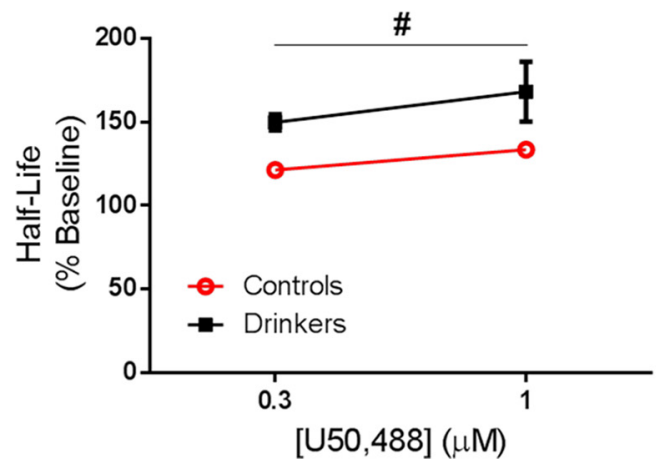

B

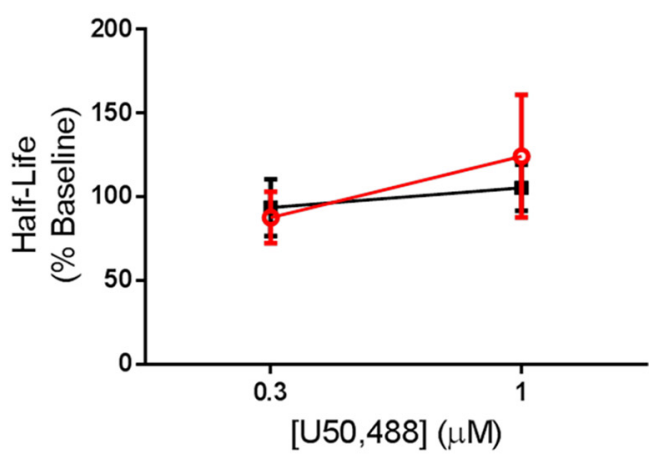

Figure 6. KOR activation decreases DA uptake in the DLC. $A$, Group data ( $n=3$ for controls; $n=6$ for drinkers) indicting U50,488-induced increases in signal half-life (i.e., decreased uptake) in the DLC. Additionally, there was a trend toward increased effects of U50,488 on DA uptake in ethanol self-administration animals. $\boldsymbol{B}$, Data ( $n=3 \mathrm{for}$ controls; $n=7 \mathrm{for}$ drinkers) indicting no effect of KOR activation on DA uptake. Error bars indicate \pm SEM. ${ }^{\#} p<0.05$ (main effect of concentration).

al., 1994; Thompson et al., 2000; Kivell et al., 2014). To assess KOR induced changes to DA clearance, we determined the halflife of voltammetric signals following application of U50,488. In the DLC, a two-way repeated measures ANOVA revealed a main effect of concentration (Fig. $6 A ; F_{(2,12)}=5.81, p=0.02$ ), but not ethanol history $\left(F_{(1,6)}=3.18, p=0.13\right)$ on half-life. In contrast, in the NAc, we did not find an effect of concentration (Fig. $6 B$; $\left.F_{(2,16)}=0.57, p=0.58\right)$ or ethanol history $\left(F_{(1,8)}=0.16, p=0.70\right)$. Thus, KOR activation slowed DA uptake rates in the DLC, but not NAc core. Additionally, ethanol self-administration had no effect on KOR-induced changes to DA uptake in either region, although there was a trend toward increased sensitivity of this effect in the DLC.

\section{Discussion}

It has been hypothesized that with continued drug use in the face of negative consequences, behavioral control of drug taking and seeking shifts from mainly involving limbic domains, such as the NAc, that mediate motivational and affective functions to those that encompass the association and sensorimotor domains, such as the dorsal striatum (Porrino et al., 2004, Graybiel, 2008). Here we demonstrate that both DA neurotransmission and KOR sensitivity are dysregulated in the NAc core and precommisural DLC of male cynomolgus macaques following 6 months of voluntary ethanol self-administration. Ethanol drinkers exhibited increased DA release and uptake in the NAc core and decreased release and uptake in the DLC, and the relative terminal function between the two regions was highly correlated with ethanol intake, suggesting that the relationship between them may be a determining factor in the development of aberrant drinking behaviors. Furthermore, KOR sensitivity was increased in drinking animals in both the NAc core and DLC compared to controls, and KOR sensitivity in the NAc core was positively correlated with ethanol intake. These data provide novel insight into ethanolinduced dysregulation of DA neurotransmission and suggest that

\section{$\leftarrow$}

(Figure legend continued.) for controls; $n=7$ for drinkers) indicating supersensitive KORs in the NAc core of drinkers. $\boldsymbol{E}$, Correlation analysis indicating no relationship between KOR sensitivity in the DLC and lifetime ethanol intake. $\boldsymbol{F}$, Correlation analysis indicating a positive relationship between KOR sensitivity in the NAc core and lifetime ethanol intake. When KOR sensitivity is highest, ethanol intake is highest. G, Group data ( $n=3$ for DLC; $n=3$ for NAccore) indicating greater KOR sensitivity in the NAc core than the DLC of control animals. $\boldsymbol{H}$, Group data ( $n=6$ for DLC; $n=7$ for NAc core) indicating greater KOR sensitivity in the NAc core than the DLC of ethanol self-administration animals. Error bars indicate \pm SEM. ${ }^{*} p<0.05$ versus control; ${ }^{* *} p<0.01$ versus control; ${ }^{* * *} p<0.001$ versus control. dopaminergic dysfunction may be mediating the increase in voluntary drinking during the early stages (first 6 months) of ethanol abuse/dependence. Importantly, these data contribute to mounting evidence that KOR antagonists may provide a novel avenue to reduce drinking behaviors in alcoholics (Sirohi et al., 2012; Walker et al., 2012).

The first major finding of this study was that voluntarily consumed ethanol resulted in supersensitivity of KOR receptors in both the NAc core and DLC. The involvement of the dynorphin/ KOR system in mediating stress responses as well as literature demonstrating that acute ethanol increases dynorphin release has led to the development of theories proposing an integral involvement of this system in mediating drinking behaviors as well as the negative subjective aspects of ethanol withdrawal (Sirohi et al., 2012; Walker et al., 2012; Berger et al., 2013). Here we show that voluntary ethanol self-administration has a unique effect on $\mathrm{KOR}$ sensitivity and regulation of DA release directly at the DA terminal. Additionally, we found that KOR sensitivity in the NAc core was positively correlated with drinking behavior, and, in conjunction with human and rodent work (Walker and Koob, 2008; Sirohi et al., 2012, Walker et al., 2012, Bazov et al., 2013), this suggests that ethanol-induced dysregulation of the dynorphin/ KOR system may drive the motivation to administer ethanol following repeated consumption. Indeed, administration of a KOR antagonist decreases the reinforcing efficacy of ethanol in ethanol-dependent animals, without altering drinking in ethanol naive animals (Walker and Koob, 2008). The dynorphin/KOR system plays a large role in regulating affective states in humans, and KOR agonists produce conditioned place aversion in rodents (Mucha and Herz, 1985; Pfeiffer et al., 1986). Thus, it is possible that the supersensitivity of this system may produce negative affective states, leading to increased consumption and motivation to administer ethanol in an attempt to ameliorate these effects with ethanol. In support of this hypothesis, ethanol-induced increases in KOR function have been linked to aversion, as measured by augmented $22 \mathrm{kHz}$ ultrasonic vocalizations in rodents (Kissler et al., 2014).

Previous reports demonstrating ethanol-induced increases in the behavioral effects of KOR antagonism have primarily compared ethanol naive controls with animals exposed to chronic intermittent ethanol vapor, to induce ethanol dependence, and have associated KOR regulation of ethanol consumption with ethanol dependence (Walker and Koob, 2008; Kissler et al., 2014). Here we show that following contingent drinking, KORs 
are functionally altered, even in animals with limited ethanol use. Indeed, even in the animal with the lowest ethanol intake (0.7 $\mathrm{g} / \mathrm{kg}$ daily average ethanol intake), the effect of U50,488 on DA release was greater than for all controls animals. Furthermore, we found that the severity of dysregulation of KORs increased proportionally with ethanol consumed. Although it remains to be determined precisely at what point increased KOR sensitivity may augment ethanol consumption, these data suggest that dysregulation of the KOR may play a role in drinking during early ethanol use.

The 6 month ethanol access time point at which these experiments were conducted represents a relatively early stage of ethanol abuse, roughly equivalent to two years of chronic ethanol consumption in humans. As alcoholism in humans typically develops after many years of abuse (Schuckit et al., 1995), these results are congruent with previous models of addiction that propose the NAc as the locus of behavioral control during early drug abuse (Graybiel, 2008; Everitt and Robbins, 2013). Furthermore, the current findings show that KOR regulation of DA release in control animals is modest, with $1 \mu \mathrm{M}$ U50,488 inducing just $\sim 10$ and $\sim 30 \%$ changes in DA release in the DLC and NAc core, respectively. This suggests that KORs have little effect on DAmediated behaviors before ethanol use, but their function is specifically augmented during excessive drinking. This is congruent with previous rodent literature showing no change in drinking behaviors in response to KOR blockade in animals without prior ethanol exposure (Walker and Koob, 2008). Together, these data suggest a threshold of activation for the KOR-mediated facilitation of drinking behaviors, which may be triggered by the robust ethanol-induced increases in KOR sensitivity observed here. Furthermore, the relationship between KOR sensitivity and drinking provides a potential mechanism for the comorbidity of early life stress and alcoholism (Enoch, 2011), as stress has been linked to increases in dynorphin/KOR system activity in both animal and human investigations (Pfeiffer et al., 1986; McLaughlin et al., 2006; Pascoe et al., 2008).

The second major finding of these experiments is that ethanol self-administration produces opposite alterations in DA neurotransmission in the DLC and NAc core, whereby evoked DA release and uptake are increased in the NAc core and decreased in the DLC of ethanol-drinking animals. DA uptake rates are critical for regulating both intracellular and extracellular DA levels through removal of DA from synapses and repackaging into vesicles; thus, increased uptake rates are likely to lead to lower extracellular DA tone and increased DA release per stimulation, as shown by the current findings and by others (Ferris et al., 2014). Because the behavioral relevance of cue-evoked (phasic) DA signaling is determined by increases relative to tonic levels, rather than absolute amplitude (Wanat et al., 2009), it is likely that increased DA release and uptake in the NAc core combine to produce greatly augmented dopaminergic output, whereas decreased release and uptake in the DLC result in similarly decreased output. Importantly, we found that the relative terminal function between the two regions (DLC/NAc core) was highly correlated with ethanol intake, suggesting that, as has been shown with psychostimulants, DA-dependent interactions between these two structures may play an important role in ethanol consumption (Belin and Everitt, 2008).

In addition to changes in baseline changes in DA uptake rate, we examined the effects of ethanol self-administration on the ability of KORs to alter DA uptake. Previous investigations of KOR-induced alterations to DA uptake rates have been conflicting, with increases (Thompson et al., 2000; Kivell et al., 2014), decreases (Das et al., 1994), and no change (Gehrke et al., 2008;
Ebner et al., 2010) being observed following KOR activation. Here we show that U50,488 produced a concentrationdependent decrease in DA uptake in the DLC while having no effect in the NAc core. In agreement with the effects of ethanol self-administration on KOR-induced reductions in DA release, there was a trend toward greater KOR effects on DA uptake in DLC of drinkers. These findings are consistent with previous results demonstrating decreased DAT density in the dorsal striatum following KOR agonist treatment (Collins et al., 2001) and suggest ethanol-induced decreases in DA uptake in the DLC may be KOR mediated.

Although it has been proposed that nonhuman primate models of ethanol abuse represent the most promising avenue for elucidating the neurobiology of alcoholism and for identifying molecular targets for pharmacotherapeutic compounds, investigations have been largely limited to behavioral, endocrine, or brain imaging analyses due to practical constraints. Here we show robust increases in KOR sensitivity following ethanol use in nonhuman primates and demonstrate that KOR sensitivity in the NAc core is positively correlated with ethanol intake. Additionally, we found regionally divergent ethanol-induced alterations to DA terminal function resulting in NAc core hyperfunction and DLC hypofunction. The relative uptake rate between the two regions was highly correlated with ethanol intake, suggesting that the relative output between these two regions may be critical in mediating drinking behaviors. These findings give novel insight into the neurobiological basis of ethanol abuse and provide potential mechanisms for aberrant drinking behaviors during early ethanol use. Importantly, this work demonstrates that KOR sensitivity is correlated with drinking behavior and, in light of previous work (Walker and Koob, 2008; Sirohi et al., 2012, Walker et al., 2012, Bazov et al., 2013), increases the confidence that KOR antagonists may provide a novel pharmacotherapy for relapse to ethanol drinking following periods of abstinence.

\section{References}

Bazov I, Kononenko O, Watanabe H, Kuntić V, Sarkisyan D, Taqi MM, Hussain MZ, Nyberg F, Yakovleva T, Bakalkin G (2013) The endogenous opioid system in human alcoholics: molecular adaptations in brain areas involved in cognitive control of addiction. Addict Biol 18:161-169. CrossRef Medline

Belin D, Everitt BJ (2008) Cocaine seeking habits depend upon dopaminedependent serial connectivity linking the ventral with the dorsal striatum. Neuron 57:432-441. CrossRef Medline

Berger AL, Williams AM, McGinnis MM, Walker BM (2013) Affective cueinduced escalation of alcohol self-administration and increased $22-\mathrm{kHz}$ ultrasonic vocalizations during alcohol withdrawal: role of kappa-opioid receptors. Neuropsychopharmacology 38:647-654. CrossRef Medline

Bossert JM, Poles GC, Wihbey KA, Koya E, Shaham Y (2007) Differential effects of blockade of dopamine D1-family receptors in nucleus accumbens core or shell on reinstatement of heroin seeking induced by contextual and discrete cues. J Neurosci 27:12655-12663. CrossRef Medline

Carelli RM (2002) The nucleus accumbens and reward: neurophysiological investigations in behaving animals. Behav Cogn Neurosci Rev 1:281-296. CrossRef Medline

Collins SL, Gerdes RM, D’Addario C, Izenwasser S (2001) Kappa opioid agonists alter dopamine markers and cocaine-stimulated locomotor activity. Behav Pharmacol 12:237-245. CrossRef Medline

Cuzon Carlson VC, Seabold GK, Helms CM, Garg N, Odagiri M, Rau AR, Daunais J, Alvarez VA, Lovinger DM, Grant KA (2011) Synaptic and morphological neuroadaptations in the putamen associated with longterm, relapsing alcohol drinking in primates. Neuropsychopharmacology 36:2513-2528. CrossRef Medline

Das D, Rogers J, Michael-Titus AT (1994) Comparative study of the effects of mu, delta and kappa opioid agonists on $3 \mathrm{H}$-dopamine uptake in rat striatum and nucleus accumbens. Neuropharmacology 33:221-226. CrossRef Medline 
Daunais JB, Kraft RA, Davenport AT, Burnett EJ, Maxey VM, Szeliga KT, Rau AR, Flory GS, Hemby SE, Kroenke CD, Grant KA, Friedman DP (2010) MRI-guided dissection of the nonhuman primate brain: a case study. Methods 50:199-204. CrossRef Medline

Di Chiara G (2002) Nucleus accumbens shell and core dopamine: differential role in behavior and addiction. Behav Brain Res 137:75-114. Medline

Ebner SR, Roitman MF, Potter DN, Rachlin AB, Chartoff EH (2010) Depressive-like effects of the kappa opioid receptor agonist salvinorin A are associated with decreased phasic dopamine release in the nucleus accumbens. Psychopharmacology (Berl) 210:241-252. CrossRef

Enoch MA (2011) The role of early life stress as a predictor for alcohol and drug dependence. Psychopharmacology (Berl) 214:17-31. CrossRef

Everitt BJ, Robbins TW (2013) From the ventral to the dorsal striatum: devolving views of their roles in drug addiction. Neurosci Biobehav Rev 37:1946-1954. Medline

Ferris MJ, Calipari ES, Yorgason JT, Jones SR (2013) Examining the complex regulation and drug-induced plasticity of dopamine release and uptake using voltammetry in brain slices. ACS Chem Neurosci 4:693-703. CrossRef Medline

Ferris MJ, España RA, Locke JL, Konstantopoulos JK, Rose JH, Chen R, Jones SR (2014) Dopamine transporters govern diurnal variation in extracellular dopamine tone. Proc Natl Acad Sci U S A 111:E2751-E2759. CrossRef Medline

Gehrke BJ, Chefer VI, Shippenberg TS (2008) Effects of acute and repeated administration of salvinorin A on dopamine function in the rat dorsal striatum. Psychopharmacology (Berl) 197:509-517. CrossRef

Grant KA, Leng X, Green HL, Szeliga KT, Rogers LS, Gonzales SW (2008) Drinking typography established by scheduled induction predicts chronic heavy drinking in a monkey model of ethanol self-administration. Alcohol Clin Exp Res 32:1824-1838. CrossRef Medline

Grant KA, Ferguson B, Helms CM, McClintick MN (2014) Drinking to dependence risk factors in nonhuman primates. In: Neurobiology of alcohol dependence (Noronha AB, Cui C, Harris RA, Crabbe JC, eds), pp 412424. Waltham, MA: Elsevier.

Graybiel AM (1995) The basal ganglia. Trends Neurosci 18:60-62. Medline

Graybiel AM (2008) Habits, rituals, and the evaluative brain. Annu Rev Neurosci 31:359-387. CrossRef Medline

Heimer L, Zahm DS, Churchill L, Kalivas PW, Wohltmann C (1991) Specificity in the projection patterns of accumbal core and shell in the rat. Neuroscience 41:89-125. CrossRef Medline

Kelly RS, Wightman RM (1987) Detection of dopamine overflow and diffusion with voltammetry in slices of rat brain. Brain Res 423:79-87. Medline

Kissler JL, Sirohi S, Reis DJ, Jansen HT, Quock RM, Smith DG, Walker BM (2014) The one-two punch of alcoholism: role of central amygdala dynorphins/kappa-opioid receptors. Biol Psychiatry 75:774-782. CrossRef Medline

Kivell B, Uzelac Z, Sundaramurthy S, Rajamanickam J, Ewald A, Chefer V, Jaligam V, Bolan E, Simonson B, Annamalai B, Mannangatti P, Prisinzano TE, Gomes I, Devi LA, Jayanthi LD, Sitte HH, Ramamoorthy S, Shippenberg TS (2014) Salvinorin A regulates dopamine transporter function via a kappa opioid receptor and ERK1/2-dependent mechanism. Neuropharmacology 86:228-240. CrossRef Medline

Le Merrer J, Becker JA, Befort K, Kieffer BL (2009) Reward processing by the opioid system in the brain. Physiol Rev 89:1379-1412. CrossRef Medline

Lemos JC, Wanat MJ, Smith JS, Reyes BA, Hollon NG, Van Bockstaele EJ, Chavkin C, Phillips PE (2012) Severe stress switches CRF action in the nucleus accumbens from appetitive to aversive. Nature 490:402-406. CrossRef Medline

Lindholm S, Rosin A, Dahlin I, Georgieva J, Franck J (2007) Ethanol alters the effect of kappa receptor ligands on dopamine release in the nucleus accumbens. Physiol Behav 92:167-171. Medline

Majchrowicz E, Mendelson JH (1970) Blood concentrations of acetaldehyde and ethanol in chronic alcoholics. Science 168:1100-1102. CrossRef Medline

Manzanares J, Lookingland KJ, Moore KE (1991) Kappa opioid receptormediated regulation of dopaminergic neurons in the rat brain. J Pharmacol Exp Ther 256:500-505. Medline

McLaughlin JP, Li S, Valdez J, Chavkin TA, Chavkin C (2006) Social defeat stress-induced behavioral responses are mediated by the endogenous kappa opioid system. Neuropsychopharmacology 31:1241-1248. Medline

Mucha RF, Herz A (1985) Motivational properties of kappa and mu opioid receptor agonists studied with place and taste preference conditioning Psychopharmacology (Berl) 86:274-280. Medline

Ongür D, Price JL (2000) The organization of networks within the orbital and medial prefrontal cortex of rats, monkeys, and humans. Cereb Cortex 10:206-219. CrossRef Medline

Pascoe JE, Williams KL, Mukhopadhyay P, Rice KC, Woods JH, Ko MC (2008) Effects of mu, kappa, and delta opioid receptor agonists on the function of hypothalamic-pituitary-adrenal axis in monkeys. Psychoneuroendocrinology 33:478-486. CrossRef Medline

Patel JC, Rice ME (2013) Monitoring axonal and somatodendritic dopamine release using fast-scan cyclic voltammetry in brain slices. Methods Mol Biol 964:243-273. CrossRef Medline

Paxinos G, Huang XF, Petrides M, Toga AW (2009) The rhesus monkey brain in stereotaxic coordinates, Ed 2. San Diego: Elsevier.

Pfeiffer A, Brantl V, Herz A, Emrich HM (1986) Psychotomimesis mediated by kappa opiate receptors. Science 233:774-776. CrossRef Medline

Porrino LJ, Lyons D, Smith HR, Daunais JB, Nader MA (2004) Cocaine self-administration produces a progressive involvement of limbic, association, and sensorimotor striatal domains. J Neurosci 24:3554-3562. CrossRef Medline

Saddoris MP, Sugam JA, Cacciapaglia F, Carelli RM (2013) Rapid dopamine dynamics in the accumbens core and shell: learning and action. Front Biosci 5:273-288. Medline

Schuckit MA, Anthenelli RM, Bucholz KK, Hesselbrock VM, Tipp J (1995) The time course of development of alcohol-related problems in men and women. J Stud Alcohol 56:218-225. Medline

Siciliano CA, Calipari ES, Ferris MJ, Jones SR (2014) Biphasic mechanisms of amphetamine action at the dopamine terminal. J Neurosci 34:55755582. CrossRef Medline

Siciliano CA, Calipari ES, Ferris MJ, Jones SR (2015) Adaptations of presynaptic dopamine terminals induced by psychostimulant self-administration. ACS Chem Neurosci 6:27-36. Medline

Sirohi S, Bakalkin G, Walker BM (2012) Alcohol-induced plasticity in the dynorphin/kappa-opioid receptor system. Front Mol Neurosci 5:95. Medline

Substance Abuse and Mental Health Services Administration (2012) National Survey on Drug Use and Health. http://www.samhsa. gov/data/NSDUH/2012SummNatFindDetTables/DetTabs/NSDUH-Det TabsSect2peTabs43to84-2012.htm\#Tab2.71B.

Thompson AC, Zapata A, Justice JB Jr, Vaughan RA, Sharpe LG, Shippenberg TS (2000) Kappa-opioid receptor activation modifies dopamine uptake in the nucleus accumbens and opposes the effects of cocaine. J Neurosci 20:9333-9340. Medline

Vivian JA, Green HL, Young JE, Majerksy LS, Thomas BW, Shively CA, Tobin JR, Nader MA, Grant KA (2001) Induction and maintenance of ethanol self-administration in cynomolgus monkeys (Macaca fascicularis): longterm characterization of sex and individual differences. Alcohol Clin Exp Res 25:1087-1097. CrossRef Medline

Walker BM, Koob GF (2008) Pharmacological evidence for a motivational role of kappa-opioid systems in ethanol dependence. Neuropsychopharmacology 33:643-652. CrossRef Medline

Walker BM, Valdez GR, McLaughlin JP, Bakalkin G (2012) Targeting dynorphin/kappa opioid receptor systems to treat alcohol abuse and dependence. Alcohol 46:359-370. CrossRef Medline

Walker JM, Thompson LA, Frascella J, Friederich MW (1987) Opposite effects of mu and kappa opiates on the firing-rate of dopamine cells in the substantia nigra of the rat. Eur J Pharmacol 134:53-59. CrossRef Medline

Wanat MJ, Willuhn I, Clark JJ, Phillips PE (2009) Phasic dopamine release in appetitive behaviors and drug addiction. Curr Drug Abuse Rev 2:195213. CrossRef Medline

Werling LL, Frattali A, Portoghese PS, Takemori AE, Cox BM (1988) Kappa receptor regulation of dopamine release from striatum and cortex of rats and guinea pigs. J Pharmacol Exp Ther 246:282-286. Medline

Yorgason JT, España RA, Jones SR (2011) Demon voltammetry and analysis software: analysis of cocaine-induced alterations in dopamine signaling using multiple kinetic measures. J Neurosci Methods 202:158-164. Medline 